\title{
Immunizations in Chronic Kidney Disease and Kidney Transplantation
}

\author{
Tara M. Babu, MD, MSCI ${ }^{1,2}$ \\ Camille N. Kotton, MD, FIDSA, FAST $T^{3, *}$
}

\author{
Address \\ ${ }^{1}$ Division of Allergy and Infectious Diseases, University of Washington, 908 Jeffer- \\ son Street, Suite 11NJ-1166, Seattle, WA, 98104, USA \\ ${ }^{2}$ Division of Infectious Diseases, University of Rochester Medical Center, Roches- \\ ter, NY, USA \\ ${ }^{*}, 3$ Transplant and Immunocompromised Host Infectious Diseases, Infectious Dis- \\ eases Division, Massachusetts General Hospital, Harvard Medical School, 55 Fruit \\ Street, Cox 5, Boston, MA, 02114, USA \\ Email:ckotton@mgh.harvard.edu
}

Published online: 17 May 2021

(C) The Author(s), under exclusive licence to Springer Science+Business Media, LLC, part of Springer Nature 2021

This article is part of the Topical Collection on New Technologies and Advances in Infections Prevention

Keywords Vaccination · Chronic kidney disease · Kidney transplant · Immunization

\section{Abstract}

Purpose of Review Infection is a significant cause of morbidity and mortality in both patients with chronic kidney disease (CKD) and in recipients of a kidney transplant (KT). We review the current data in patients with CKD, on dialysis, and in KT recipients to provide further guidance for clinicians regarding vaccine optimization in this patient population.

Recent Findings This patient population remains under-vaccinated and thus more vulnerable to vaccine-preventable illness. Despite diminished responses to immunization in this population, significant protection is generally achieved.

Summary Vaccines are an important preventative tool and offer protection against infection. In the setting of suboptimal and waning immunity in this patient population, future studies are indicated to determine optimal vaccination regimens.

\section{Introduction}

Patients with chronic kidney disease (CKD) and kidney transplants (KT) are more vulnerable to vaccinepreventable illness, with potential for worsening of kidney disease, significant morbidity, and mortality. Unfortunately, this population remains significantly under-vaccinated. Non-live vaccines are generally very safe; 
live vaccines can be given before (or after cessation of) immunosuppression (Table 1). Although less immunogenic in this population, vaccines likely provide some measure of protection and positively influence clinical outcomes. This review is intended to help guide clinicians toward optimal vaccination of this vulnerable population.

Table 1. Vaccine recommendations for CKD and KT patients [1-12]

\begin{tabular}{|c|c|c|c|c|}
\hline Vaccine & Type & Safe pre-transplant ${ }^{1}$ & Safe post-transplant & $\begin{array}{l}\text { Clinical } \\
\text { response } \\
\text { monitoring }\end{array}$ \\
\hline Influenza $^{a}$ & I (intradermal) & Yes & Yes & No \\
\hline Influenza & LAIV (intranasal) & Yes & No & No \\
\hline Hepatitis $B^{b}$ & $\mathrm{I}$ & Yes & Yes & Yes \\
\hline Hepatitis A & I & Yes & Yes & Yes \\
\hline Tetanus/diphtheria & I & Yes & Yes & No \\
\hline Pertussis & I & Yes & Yes & No \\
\hline Measles, mumps, rubella & LAIV & Yes & No & Yes \\
\hline Varicella & LAIV & Yes & No & Yes \\
\hline $\begin{array}{l}\text { Zoster } \\
(\text { Zostavax })^{c}\end{array}$ & LAIV & Yes & No & No \\
\hline $\begin{array}{l}\text { Zoster } \\
(\text { Shingrix })^{c}\end{array}$ & I & Yes & -- & No \\
\hline $\begin{array}{l}\text { Pneumococcal } \\
\text { (PCV13) }\end{array}$ & I & Yes & Yes & No \\
\hline $\begin{array}{l}\text { Pneumococcal } \\
\text { (PPSV23) }\end{array}$ & I & Yes & Yes & No \\
\hline Meningococcus & I & Yes & Yes & No \\
\hline Human papillomavirus virus & I & Yes & Yes & No \\
\hline $\begin{array}{l}\text { Polio }^{d} \\
\text { (IPV) }\end{array}$ & I & Yes & Yes & No \\
\hline Haemophilus influenza & I & Yes & Yes & No \\
\hline Rabies & I & Yes & Yes & Yes \\
\hline $\begin{array}{l}\text { Typhoid } \\
\text { ViCPS (Typhim Vi, Sanofi Pasteur) }\end{array}$ & $\begin{array}{l}\text { I } \\
\text { (intradermal) }\end{array}$ & Yes & Yes & No \\
\hline $\begin{array}{l}\text { Typhoid } \\
\text { Ty21a (Vivotif, Swiss PaxVax) }\end{array}$ & $\begin{array}{l}\text { LAIV } \\
\text { (oral) }\end{array}$ & Yes & No & No \\
\hline Cholera & LAIV & Yes & No & No \\
\hline Japanese encephalitis & I & Yes & Yes & No \\
\hline Yellow fever & LAIV & Yes & No & No \\
\hline $\begin{array}{l}\text { I, inactivated vaccine; LAIV, live atte } \\
{ }^{1} \text { When indicated vaccination series ar } \\
{ }^{a} \text { Influenza higher dose influenza vacc } \\
{ }^{\mathrm{b}} \text { Hepatitis B vaccine both HD patients } \\
\text { HB or Engerix-B } \\
{ }^{\mathrm{c} S h i n g r i x ~ i s ~ t h e ~ p r e f e r r e d ~ Z o s t e r ~ v a c c i ~} \\
{ }^{\mathrm{d}} \text { Polio IPV only polio vaccine licensed }\end{array}$ & $\begin{array}{l}\text { luated vaccine } \\
\text { preferred to be com } \\
\text { ination should be con } \\
\text { and KT patients shoul }\end{array}$ & $\begin{array}{l}\text { ted prior to transplantation } t \\
\text { ered for transplant recipients } \\
\text { eceive the higher dose vaccin } \\
\text { tion }\end{array}$ & $\begin{array}{l}\text { ncrease efficacy } \\
\text { it } 40 \text { mcg of HBV surface ant }\end{array}$ & for Recombivax \\
\hline
\end{tabular}




\section{Timing of vaccination}

Vaccines tend to be most effective early in the course of renal disease and are more likely to confer protection prior to transplant and immunosuppression [13]. A trial of live zoster vaccine in subjects $\geq 60$ years old on dialysis found better vaccine protection if given within 2 years of dialysis initiation [14]. After transplant, vaccination is less likely to confer protection in the first year after transplant, and during periods of more intense immunosuppression; if vaccines are given during these times, repeat vaccination once the patients are less immunosuppressed may help provide more optimal protection. One study in organ transplant recipients showed that a response to influenza vaccine was more likely in those more than 6 months after transplant $(53.2 \%$ vs. $19.2 \% ; p=$ $0.001)$ [15]. The majority of transplant programs give influenza vaccine starting within the first 3-6 months after transplant [16]. When possible, avoiding periods of higher doses of mycophenolate mofetil may result in better protection $[15,17]$. Although formal studies have not been done, for those on rituximab, vaccination 2-4 weeks before the next dose of rituximab may result in a better immune response. Tables 2 and 3 show the current recommended vaccine schedules for adults in the USA.

\section{Concerns regarding untoward effects of vaccination on autoimmune disease and transplant outcomes}

While there has been a theoretical concern that vaccination could increase the risk of autoimmune disease or kidney rejection, no studies have shown clinically significant allograft dysfunction, and/or loss of graft tolerance (reviewed in guidelines [1]). HLA antibody formation has been reported at very low rates after influenza vaccine, but it has not been shown to cause rejection $[15,18,19]$. While there has been concern that adjuvants, intended to be immunostimulatory, could have untoward effects in transplant recipients, no clinical data support this theory. In a trial of adjuvanted and non-adjuvanted influenza vaccine, there were no increases in HLA alloantibodies in patients who received adjuvanted vaccine, although it did show a potential immunogenicity benefit for those 18 to 64 years of age [20]. Similarly, a trial of KT recipients given either a non-adjuvanted influenza vaccine or a squalene-based AS03or MF59-adjuvanted vaccine found no differences in graft function after vaccination [21]. Overall, the preponderance of data suggests significant protection and safety with vaccination in patients with chronic kidney disease (CKD).

\section{Routine vaccines}

Influenza vaccine is recommended every year for all patients with CKD [22]. While the response is diminished in those with CKD and those on renal replacement therapy compared with normal hosts, the response is likely adequate to provide reasonable protection [23]. A review conducted over a decade in Taiwan of patients with systemic lupus erythematosus, of who a small minority were vaccinated, found that those who had been vaccinated against 
Table 2. Adult immunization recommendations by age group, United States 2021. Reprinted from Advisory Committee on Immunization Practices. Recommended adult immunization schedule for ages 19 years or older, United States, 2021. Centers for Disease Control and Prevention. Available at: https://www.cdc.gov/vaccines/schedules/hcp/imz/adult.html (Accessed on May 13, 2021)

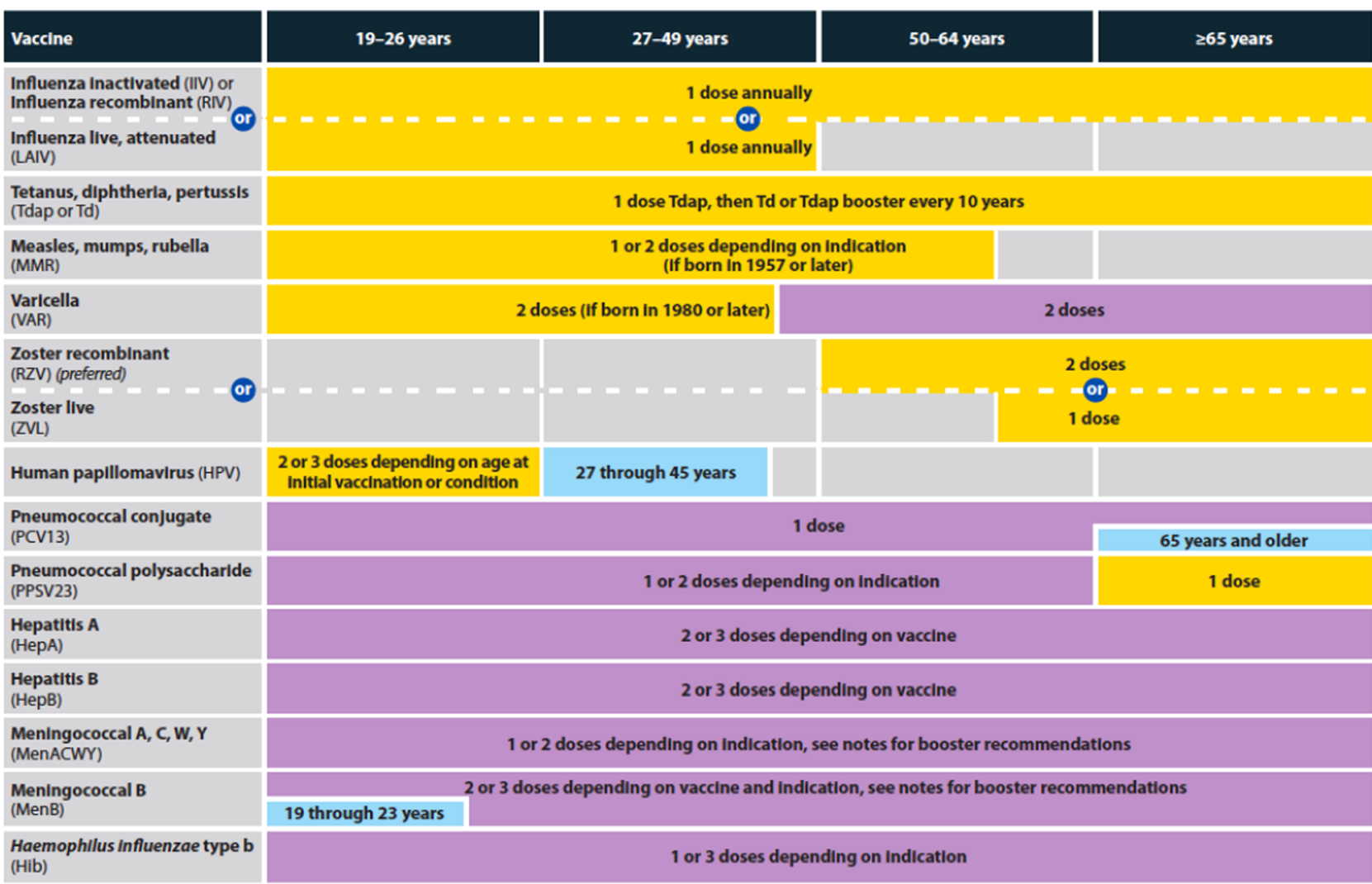

influenza had lower hospitalization rates; lower likelihood of being admitted to intensive care units and hospitalized for septicemia, bacteremia, or viremia; and lower likelihood to undergo in hospital dialysis and experience death, suggesting a significant reduction in morbidity and mortality with vaccination [24].

Dialysis centers are systematically able to deliver vaccines, and this is an essential infection control measure. Consequently, patients in dialysis centers tend to get higher rates of vaccination compared with those not in dialysis centers [25]. In a study of hemodialysis (HD) patients with diabetes, $17 \%$ of the non-vaccinated patients develop clinical influenza compared with $6.3 \%$ among those who were vaccinated $(p=0.026)$ [25]. A trial comparing non-adjuvanted influenza vaccine with vaccine adjuvanted with MF59 found higher rates of seroconversion after adjuvant vaccine in patients on dialysis, suggesting this may provide better clinical protection [26]. 
Table 3. Adult recommendations based on medical conditions, United States 2021. Reprinted from Advisory Committee on Immunization Practices. Recommended adult immunization schedule for ages 19 years or older, United States, 2021. Centers for Disease Control and Prevention. Available at: https://www.cdc.gov/vaccines/schedules/hcp/imz/adult.html (Accessed on May 13, 2021)

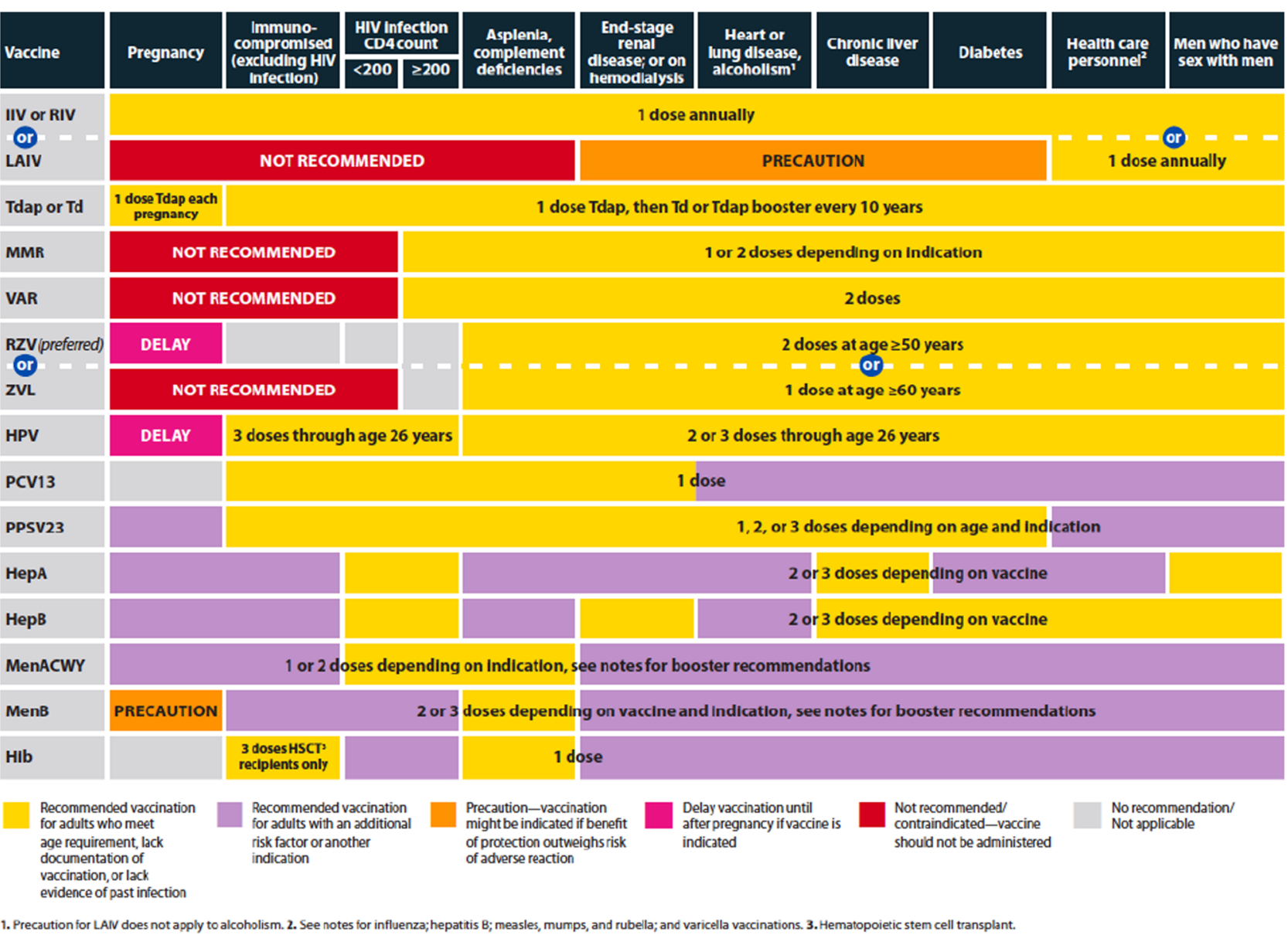

After a kidney transplant, recommendations suggest vaccinating against influenza can start 3-6 months later $[1,16,27]$. In a series of over 50,000 Medicare recipients given influenza vaccine within the first year after kidney transplant, vaccination was associated with lower risk of subsequent allograft loss and death; claims for influenza infection were reported in $310(0.6 \%)$ patients and were not significantly associated with graft loss, although there was a trend toward death [28]. Analysis of a recent outbreak of influenza A in a KT unit showed that lack of vaccination significantly increased both the risk of influenza infection (odds ratio 37.5) and mortality (odds ratio 6.7) [29].

A recent trial of high-dose compared with standard-dose influenza vaccine in solid organ transplant recipients demonstrated significantly better immunogenicity with high-dose vaccine, suggesting this may be the preferred influenza vaccine for this population [30]. Intradermal administration of high-dose 
vaccine may provide potential enhanced immunogenicity, although is not standardly recommended $[15,19]$. Data are currently insufficient to recommend use of booster dose (within the same season), although with recent transplantation or potent immunosuppression, such approaches could be considered $[16,19]$. As discussed above, adjuvanted vaccine seems to be as safe as non-adjuvanted and could provide better protection. Most importantly, all transplant recipients and their household members should be vaccinated every year. Unfortunately, due to misconceptions and lack of understanding about safety, this population remains under-vaccinated. In addition, vaccination of healthcare professionals caring for patients with kidney disease is an important infection control measure.

Hepatitis B virus (HBV) acquisition was once the scourge of dialysis centers. With strict infection control measures and HBV vaccination, the rates of hepatitis B infection in dialysis patients have declined dramatically. Nonetheless, patients on dialysis remain at risk for exposure to blood-borne pathogens, especially in more endemic regions. Numerous guidelines recommend hepatitis $B$ vaccination of patients with CKD, including those not yet on dialysis, as well as those on hemodialysis, peritoneal dialysis, and home dialysis [22, 31]. Unfortunately, adults with kidney disease generally have a poor response to $\mathrm{HBV}$ vaccine. Adults on hemodialysis should be given a 3-dose series of Recombivax $\mathrm{HB} 40 \mu \mathrm{g}$ at 0,1 , and 6 months or a 4-dose series of Engerix-B $40 \mu \mathrm{g}$ at $0,1,2$, and 6 months [22]. Although less well studied, similar vaccination would be indicated for non-hemodialysis CKD patients; some clinicians may wish to start with standard-dose vaccination and if inadequate seroconversion, repeat the series with higher dose vaccine. Clinically significant HBV infection has been documented in hemodialysis patients who initially responded but did not maintain anti-HBs concentrations of $>10 \mathrm{mIU} / \mathrm{mL}$, suggesting a need for periodic monitoring and boosters [32].

There are five inactivated hepatitis B vaccines currently recommended for use in the USA. The most recently recommended vaccine is HepB-CpG, which is prepared by combining purified recombinant hepatitis $B$ surface antigen with small synthetic immunostimulatory cytidine-phosphate-guanosine oligodeoxynucleotide (CpGODN) motifs (1018 adjuvant). This 1018 adjuvant binds to Toll-like receptor 9, which in turn stimulates a directed immune response to hepatitis B surface antigen [33]. Multiple studies show better immunologic response compared with prior vaccines [33]. In a study of almost 500 hemodialysis patients, 3 doses of HepBCpG induced significantly higher seroprotection, earlier seroprotection, and more durable seroprotection than 4 double doses of Engerix-B; it has a similar safety profile and was generally well tolerated [34].

A small subset of patients often remains refractory to HBV vaccination, even after a repeat high-dose vaccination series. Repeat vaccination is often recommended, with limited success. Clinically the presence of humoral immunity is a primary determinant in evaluation vaccine response. Cell-mediated immunity plays a role in vaccine response. The presence of cell-mediated immunity against HBV was examined in $51 \mathrm{KT}$ recipients and 22 healthy controls with varying humoral antibody response to HBV surface antigen (HBs-Ag) [35]. 
HBsAg-specific Th cells were detected in 50\% of patients without evidence of humoral immunity (HBsAg-antibody), suggesting protection even without seroconversion. A small study evaluating the efficacy of the adjuvanted hepatitis B vaccine Fendrix ${ }^{\mathrm{TM}}$, approved in Europe, has shown promising results in KT recipients. Seventeen KT non-responders to prior HBV vaccine series received one dose of Fendrix ${ }^{\mathrm{TM}}$ [36]. At 1-month post vaccination, 7 out of 17 (41\%) recipients demonstrated anti-HBV surface antibodies $\geqq 10 \mathrm{IU} / \mathrm{L}$ and 10 out of 17 (59\%) recipients had evidence of humoral and/or cell-mediated immunity [36].

Pneumonia is associated with poor outcomes and increased mortality in patients with CKD $[37,38]$. Kidney disease predisposes to higher rates of pneumococcal infection, and all CKD and KT patients should receive both pneumococcal conjugate vaccine (PCV13) and pneumococcal polysaccharide vaccine (PPSV23) [22]. Both vaccines are immunogenic in patients on dialysis, particularly when the recipients are naïve to the pneumococcal vaccine [39].

The Advisory Committee on Immunization Practices (ACIP) guidelines recommend that CKD and KT patients aged 19 years or older, naïve to PCV13, should receive PCV13 followed by PPSV23 (at least 8 weeks later) [40]. Patients who have previously received PPSV23 should be given PCV13 (at least 1 year after PPSV23). If younger than 65 years of age, patients should receive a 5-year booster PPSV23 following the initial PPSV23 [40, 41]. At age 65 years old, an additional PPSV23 is recommended if the vaccine series was initiated before 65 years of age. In countries with varying pneumococcal serotype vaccines, national guidelines should be followed.

Evidence is limited on the immunogenicity of the pneumococcal vaccines in CKD and HD patients. Over time, anti-pneumococcal antibody wanes in end-stage renal disease patients following both PPSV23 and PCV13 administration [42,43]. When compared to PPSV23, PCV13 demonstrated higher immunogenicity. In a phase IV study of PPSV23naïve or vaccinated HD patients, significant antibody responses against most pneumococcal vaccine serotypes were present at 1-year post-administration of the PCV13 or PPSV23 [39]. In PPSV23-naïve patients, PCV13 elicited significantly higher antibody levels compared to PPSV23, 1.852.34-fold, for six serotypes at 28 days. At 1-year post PCV13, antibody response to ten serotypes was significantly higher, 1.44-3.29-fold, among PPSV23-naïve compared to PPSV23 pre-vaccinated patients [39].

PCV13 has shown immunogenicity in KT recipients [44]. In a study of KT recipients $(n=45)$ following PCV13, with $77 \%$ had previously received PPSV23, a median 1.1- to 1.7-fold increase in antibody against all 13 pneumococcal vaccine serotypes was observed at 4 weeks post vaccination [44]. The study also confirmed the safety of the PCV13, with no evidence of de novo antihuman leukocyte antigen antibodies, no biopsy-proven rejection, and no reported cases of invasive pneumococcal infection [44]. PPSV23 immunogenicity wanes over time in KT recipients; the degree of decrease reported is variable in long-term studies $[45,46]$. In a study of KT recipients $(n=49)$ administered PPSV23, the anti-pneumococcal antibody response at 15 months was $77 \%$ of the response at 1 month post vaccination [46]. 


\section{Tetanus, pertussis, and diphtheria vaccines}

The ACIP recommends one dose of acellular adult vaccine for pertussis in combination with tetanus and diphtheria (Tdap) for adults and adolescents. Following one dose of Tdap, tetanus and diphtheria toxoid (Td) vaccine is recommended every 10 years or earlier in the setting of wound care [47]. In adults $\geqq 19$ years without prior tetanus, diphtheria, and pertussis vaccinations, the preferred schedule is one dose of Tdap, followed by 1 dose of either Td or Tdap at least 4 weeks afterward, and one final dose of either Td or Tdap 612 months later [47]. Two Tdap vaccines are licensed for use in the USA; Boostrix (GlaxoSmithKline) and Adacel (Sanofi Pasteur) are approved for persons $>10$ years and 10-64 years, respectively.

While diphtheria and tetanus are uncommon diseases in the USA, pertussis is considered endemic to the USA and the incidence of pertussis has increased worldwide over the last 20 years. The existing data suggest that the tetanus vaccine has lower immunogenicity in CKD patients as compared to individuals with normal renal function [48]. In a study of HD patients $(n=40)$ without preliminary antibody to tetanus toxoid, following one dose of tetanus or tetanus-diphtheria vaccine, 15 (38\%) patients seroconverted while 25 (63\%) patients did not respond. The response to diphtheria toxoid was correlated with the response tetanus toxoid $(p<0.04)$ [49].

In a study of KT patients $(n=164)$ administered the tetanus-diphtheria booster vaccine, all patients developed a protective antibody to tetanus at 4 weeks post vaccination. At 1 -year post booster vaccine, tetanus antibody levels waned; however, all patients $(n=55)$ maintained protective levels $(\geqq$ $0.01 \mathrm{IU} / \mathrm{mL}$ ). Following the tetanus-diphtheria booster, $88.5 \%$ of KT recipients developed diphtheria toxoid antibody, compared to $96.2 \%$ of healthy controls at 4 weeks post vaccination. By 1 year, $38 \%$ of KT recipients had low diphtheria antitoxin titers under the protective level $(0.1 \mathrm{IU} / \mathrm{mL})[50]$.

\section{Measles, mumps, and rubella vaccines}

Measles and mumps outbreaks continue to occur worldwide. An increase in measles and mumps cases has been observed in the USA due to unvaccinated populations and returning travelers. The measles, mumps, and rubella (MMR) vaccine is recommended in solid organ recipients prior to transplantation if the patient does not demonstrate evidence of serologic immunity [51]. In seronegative adults, practices vary on a two-dose total regimen versus a 1 dose regimen followed by confirmation of serologic conversion $>4$ weeks post vaccination [51]. Immunizing women of childbearing age prior to transplantation is important in preventing congenital rubella syndrome. The current guidelines recommend that vaccination should be planned at a minimum of 4 weeks prior to transplantation due to concerns regarding immunosuppression precipitating vaccine complications if given close together.

In pediatric kidney disease patients $(n=10)$ on dialysis given the MMR vaccination, the protective titers for measles, mumps, and rubella were $70 \%$, $50 \%$, and $80 \%$ [52], respectively. Only $30 \%$ of patients responded to all 3 components of the vaccine as compared to $90 \%$ of healthy controls [52]. Some evidence exists on the safety of the MMR vaccine in pediatric liver recipients [53, 54]; however, there is no data in adult KT recipients. The MMR vaccine is contraindicated post transplantation when on active immunosuppression. 
Kidney patients non-immune to varicella (i.e., never had chickenpox and/or are varicella seronegative) and not on active immunosuppression (i.e., not after kidney transplant) should be given two doses of vaccine 4-8 weeks apart, or a second dose if they previously received only 1 dose. Adults from the tropics are at higher risk for being non-immune to varicella. Vaccine should be avoided in those with blood dyscrasias, hematologic and lymphatic malignancies; primary or acquired immunodeficiencies, cellular immunodeficiencies, and hypogammaglobulinemia; on high-dose systemic immunosuppressive therapy (to be determined by clinician), including persons on oral steroids $>2 \mathrm{mg} / \mathrm{kg}$ of body weight or a total of $>20 \mathrm{mg} /$ day of prednisone or equivalent when administered for $>2$ weeks, although they may be vaccinated once steroid therapy has been discontinued for $>1$ month, as per usual recommendations for live-virus vaccines $[1,55]$.

Patients with kidney disease are more likely to develop shingles. In Taiwan, a retrospective cohort study of the national health insurance register database showed that KT recipients (compared with controls without kidney disease) had the highest risk of zoster (hazard ratio 8.46; 95\% CI 5.85-12.2), followed by those on peritoneal dialysis (hazard ratio $3.61 ; 95 \%$ CI 2.49-4.83) and hemodialysis (hazard ratio 1.35; 95\% CI 1.18-1.55) [56]. A recent study found that the 36-month cumulative risk of zoster among unvaccinated adults $\geq 60$ years on dialysis was $6.6 \%$, or a rate of 22.3 per 1000 person-years [14]. Vaccination with Zostavax conveyed a reduced risk of zoster (adjusted HR= 0.49 ; 95\% CI, .29-.85), with better protection if the vaccine is given within 2 years of starting dialysis [14].

Kidney patients should be vaccinated with either the recombinant, adjuvanted (non-live) shingles vaccine (Shingrix, GlaxoSmithKline) for immunocompetent patients $>50$ years old, or the live viral vaccine (Zostavax, Merck) (approved for use in $>50$ years old, recommended in those $>60$ years old), which is being phased out due to the availability of Shingrix. The efficacy of Shingrix in non-immunocompetent subjects is limited but seems to be safe [57]. Zostavax should not be used with primary or acquired immunodeficiency, or with potent immunosuppressive therapy (including antitumor necrosis factor agents) similar to the guidelines above for varicella vaccine; this would exclude safe use in most KT recipients [2]. Treatment with low doses of methotrexate $(<0.4 \mathrm{mg} / \mathrm{kg} /$ week $)$, azathioprine $(<3.0 \mathrm{mg} / \mathrm{kg} /$ day $)$, or 6 mercaptopurine $(<1.5 \mathrm{mg} / \mathrm{kg} /$ day $)$ for various autoimmune diseases is not considered sufficiently immunosuppressive and is not contraindications for administration of zoster vaccine [2]; note that this guidance refers to those on monotherapy, and the impact of additional immunosuppression from ESRD is not clear.

\section{Severe acute respiratory syndrome coronavirus-19}

The early outcomes of transplant patients with SARS-CoV-2 suggest they are at higher risk for severe disease and death [58-63] [1, 2]. Additionally, preliminary data suggest worse outcomes in CKD patients with SARS-CoV-2 infection [6466]. Vaccine platforms under investigation include RNA, DNA, recombinant 


\section{Special and travel-related vaccines}

\section{Meningococcal vaccine}

protein, viral vector based, inactivated viral vaccine and live attenuated virus [67]. At the time of this publication, the Pfizer and Moderna mRNA vaccines and Janssen/Johnson \& Johnson adenovirus vector vaccine are approved for Emergency Use Authorization (EUA) in the United States. SOT recipients were not included in the Phase 3 studies for the three EUA vaccines, however, preliminary data from SOT recipients ( $\mathrm{n}=741,49 \% \mathrm{KT}$ recipients) who have received 2 doses of the Pfizer or Moderna mRNA vaccines suggest a reactogenicity profile similar to that observed in immunocompetent hosts in the Phase 3 studies [3]. Efficacy rates may be lower in immunocompromised individuals than the general population for any of the available EUA vaccines. In a recent cohort study of 436 transplant recipients, 31/219 (14\%) KT recipients had detectable SARS-CoV-2 spike antibody following only one dose of an mRNA EUA vaccine [4]. Given the ongoing pandemic and the risk for severe COVID-19 infection in CKD and SOT KT transplant recipients, the benefit of vaccination outweighs the risk of SARS-CoV-2 infection in this patient population. Further data on long term outcomes and vaccine efficacy are needed in CKD and transplant recipients.

Those who have undergone splenectomy and who have been given eculizumab are at increased risk for meningococcal disease. If either splenectomy or eculizumab therapy is anticipated, vaccination should be considered; pretransplant is preferable, given the likelihood of improved immunogenicity. Otherwise, vaccination should be given prior to splenectomy or eculizumab, when possible. Recommendations are for 2 doses of quadrivalent vaccine (against serogroups A, C, Y, and W, either polysaccharide or conjugate) [68] and 2 doses of serogroup B vaccine [69]. Recent work showed an attenuated response in SOT recipients to both polysaccharide and conjugate quadrivalent meningococcal vaccine with no more than a $50 \%$ response, suggesting additional measures should be implemented for those at high risk of disease (i.e., antibiotic prophylaxis with penicillin or if allergic, azithromycin or ciprofloxacin) [70, 71].

Hepatitis A vaccine

Hepatitis A virus (HAV) vaccine is indicated for adults at increased risk of infection, including those with liver disease, men who have sex with men, travelers to endemic regions, and others [68, 72]. HAV vaccine has variable immunogenicity in immunocompromised hosts $[3,73]$ and clinicians may wish to ensure that two doses are given and that serology is checked, or consider giving gamma globulin if high-risk exposure is imminent [72].

\section{Travel-related vaccines}

Travel-related recommendations for immunocompromised travelers are reviewed in the Immunocompromised Travelers chapter in the 2020 Yellow Book [72]. Advice for specific travel destinations and updated disease outbreak information is available through the Centers for Disease Control website at https://wwwnc.cdc.gov/travel. 


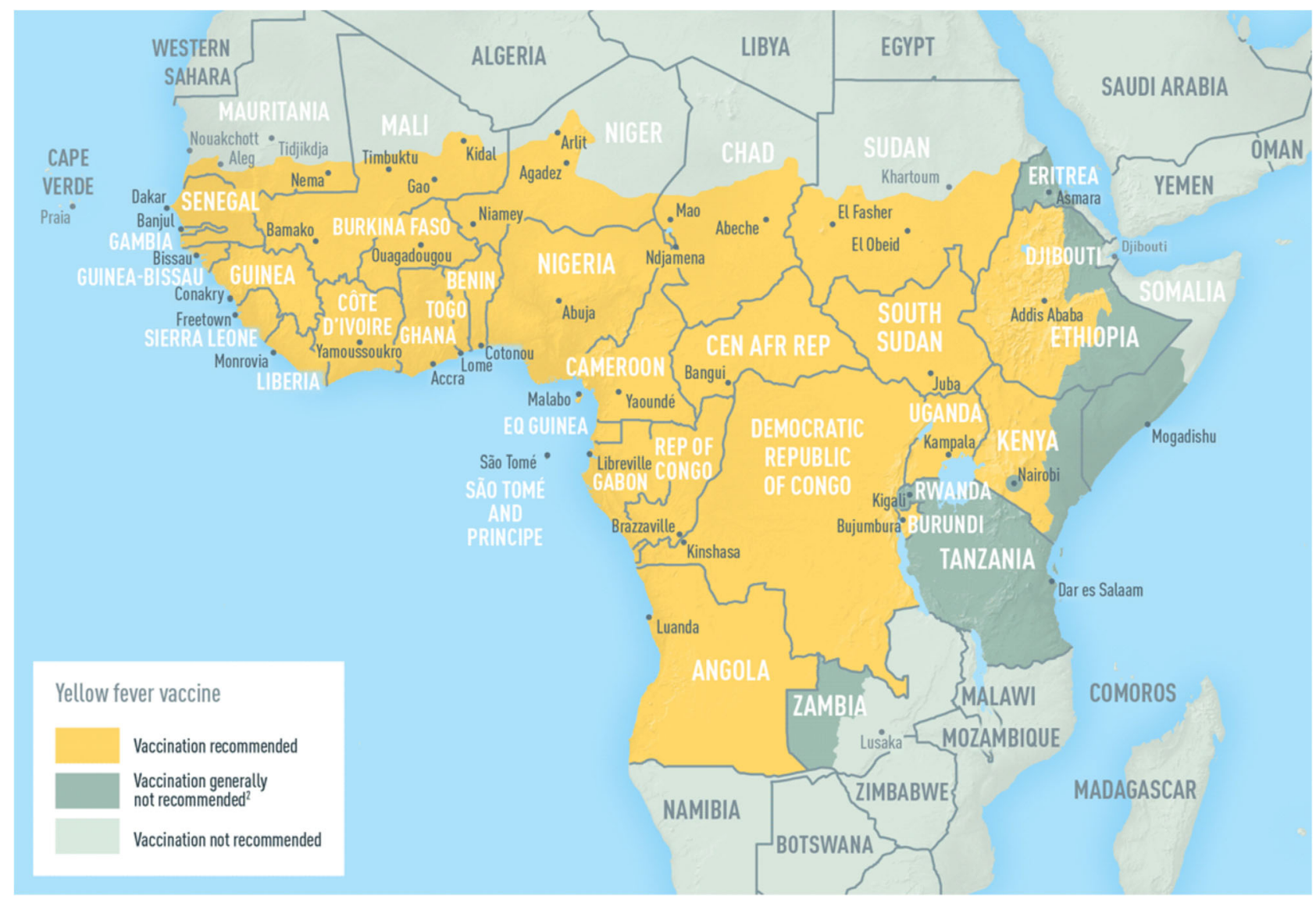

Fig. 1. a Regions at risk for Yellow Fever Acquisition in Africa (current as of August 2018). This map is an updated version of the 2010 map created by the Informal WHO Working Group on the Geographic Risk of Yellow Fever. Yellow fever (YF) vaccination is generally not recommended in areas where there is low potential for YF virus exposure. However, vaccination might be considered for a small subset of travelers to these areas who are at increased risk for exposure to YF virus because of prolonged travel, heavy exposure to mosquitoes, or inability to avoid mosquito bites. Consideration for vaccination of any traveler must take into account the traveler's risk of being infected with YF virus, country entry requirements, and individual risk factors for serious vaccineassociated adverse events (e.g., age, immune status). Reprinted from: Gershman MD, Staples JE. Travel-Related Infectious Diseases: Yellow Fever. In: CDC Yellow Book 2020, Brunette GW, Nemhauser JB (Eds), Oxford University Press, New York 2019. Available at: https://wwwnc.cdc.gov/travel/yellowbook/2020/table-of-contents (Accessed on June 13, 2020). b Regions at risk for Yellow Fever Acquisition in South America (current as of August 2018). This map is an updated version of the 2010 map created by the Informal WHO Working Group on the Geographic Risk of Yellow Fever. In 2017, CDC expanded yellow fever vaccination recommendations for travelers to Brazil because of a large outbreak of yellow fever in multiple states in that country. Please refer to the CDC Travelers' Health website (www.cdc.gov/travel) for more information and updated recommendations. Yellow fever (YF) vaccination is generally not recommended in areas where there is low potential for YF virus exposure. However, vaccination might be considered for a small subset of travelers to these areas who are at increased risk for exposure to YF virus because of prolonged travel, heavy exposure to mosquitoes, or inability to avoid mosquito bites. Consideration for vaccination of any traveler must take into account the traveler's risk of being infected with YF virus, country entry requirements, and individual risk factors for serious vaccineassociated adverse events (such as age or immune status). Reprinted from: Gershman MD, Staples JE. Travel-Related Infectious Diseases: Yellow Fever. In: CDC Yellow Book 2020, Brunette GW, Nemhauser JB (Eds), Oxford University Press, New York 2019. Available at: https://wwwnc.cd.gov/travel/yellowbook/2020/table-of-contents (Accessed on June 13, 2020). 


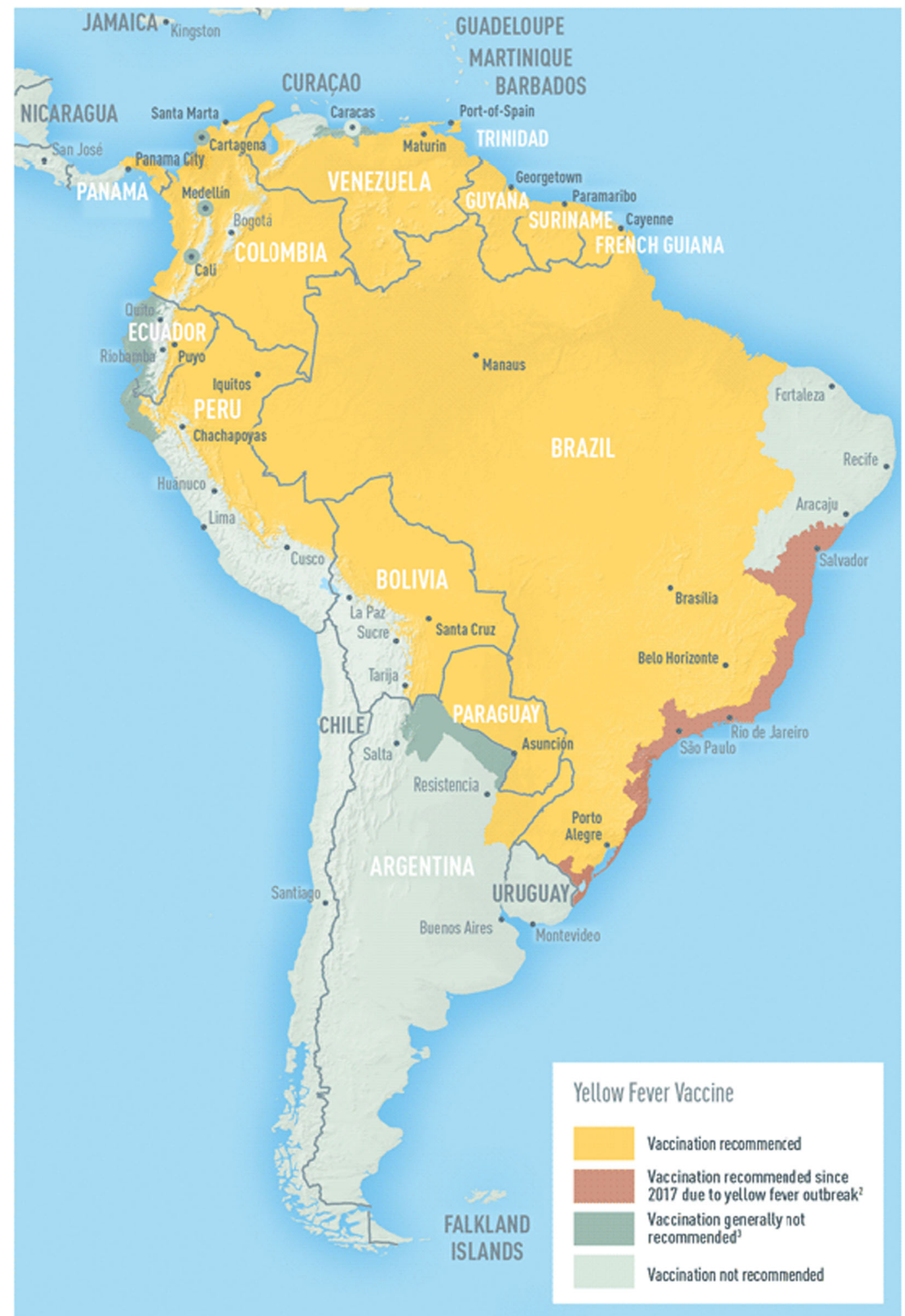

Fig. 1b (Continued) 
Yellow fever zones exist in South America and sub-Saharan Africa (Fig. 1). Immunocompromised patients should not be given yellow fever vaccine [4]. If travel to yellow fever zones is anticipated after transplant, pre-transplant vaccination should be considered (with a minimum 1-month period before the advent of immunosuppression). For non-vaccinated transplant recipients traveling to yellow fever zones, they need a yellow fever waiver on an official yellow card, in order to cross international borders. They should be instructed in methods to avoid mosquito bites, and travel during the periods of lower disease transmission. It should be recognized that yellow fever might be transmitted even during the dry season, and in both rural and urban areas [74]. In one series from Brazil, 19 SOT recipients were vaccinated without significant side effects [75]; the risk/benefit ratio is different for those living in endemic regions, compared with travelers. A retrospective analysis of SOT recipients vaccinated at some point before transplant found that all but 1/53 (98\%) had protective titers of antibodies after a median duration of 3 years (range, $0.8-21$ years) after transplantation, and that yellow fever antibodies were still detectable after a median time of 13 years (range 2-32) post-immunization [76].

In general, there is a paucity of data on travel-related vaccines in KT recipients. While vaccination would be recommended, safety and efficacy data are generally not available. Injectable typhoid fever vaccine is preferred over the live oral vaccine. Although not needed for most travelers, Japanese encephalitis vaccine should be given when indicated.

\section{Cholera vaccine}

A cholera vaccine is now available in the USA. Vaxchora prevents severe diarrhea caused by the most common type of cholera bacteria. CDC recommends adults traveling to areas with active cholera transmission get the vaccine, which is taken orally, 10 days before traveling. Inactivated cholera vaccines are available outside the USA. In a trial evaluating oral whole-cell/recombinant B subunit cholera vaccine Dukoral, transplant recipients had a less robust response, but over half seroconverted and it appeared safe [77].

\section{Passive protection when vaccination not possible}

After transplant or with other immunosuppression, live viral vaccines may not be safe and are generally deferred. Passive protection with immunoglobulins should be considered for non-immune transplant recipients with significant disease exposure. Varicella prevention could include the use of acyclovir, and/or VariZIg [78]. For measles protection, gamma globulin $0.5 \mathrm{~mL} / \mathrm{kg}$ (maximum $15 \mathrm{~mL}$ ) or IGIV $400 \mathrm{mg} / \mathrm{kg}$ can be given; although there are no recommendations, this may also be helpful with mumps and rubella exposures when vaccination is not possible. Immunoglobulin therapy is not needed for those already on treatment with IVIG. In certain situations, for patients on low dose immunosuppression and at high risk of disease, clinicians might cautiously consider the use of live viral vaccines [79]. 


\section{Biologic therapies}

The direct effect of biologics on vaccine response in KT is not well studied and is difficult to ascertain due to the combination of immunosuppressing medications used in transplantation. However as discussed previously, immunosuppression following KT does decrease vaccine response. In a study of pediatric KT recipients $(n=155)$, rituximab administration increased the risk of post vaccination titer loss with an OR: $4.26(p=$ 0.033 ) [80]. Vaccination prior to immunosuppression, ideally prior to transplant, optimizes immune response to the vaccine. Additionally, prophylactic antimicrobial therapies are often implemented based on the biologic administered.

\section{Vaccination of healthcare workers and household members of transplant recipients}

Given possible transmission through close contact, the following vaccines should be deferred in healthcare workers and household members of transplant recipients when possible: live intranasal influenza, oral polio, and smallpox. Other live attenuated vaccines are unlikely to result in transmission from normal host to immunocompromised host, including varicella, zoster, MMR, yellow fever, and typhoid fever [1]. Transplant recipients caring for infants who have been given rotavirus vaccine should defer diaper changing for 1-2 weeks and otherwise enact scrupulous hand hygiene.

\section{Administration and encouraging uptake of vaccines}

We encourage clinicians to review vaccination status as part of routine office visits, either directly by the clinician, or by other providers or staff in the office. Unfortunately, reimbursement for vaccines is often poor, such that many clinicians are less engaged with providing them in their office. Many commercial pharmacies now provide a fairly extensive array of vaccines, amplifying our capacity to give vaccines outside of our offices, especially in a time when many of us are practicing more virtual medicine.

Patients should be aware of the extensive safety of vaccines and the risks of vaccine-preventable illness, including the negative impact on their kidney function. Posters and other educational materials in clinic and transmitted via patient messaging portals may be helpful. In a trial in Germany in older patients with chronic renal disease, while messaging physicians about the need for vaccination did not have an impact, messaging directly to patients was effective [81]. 


\section{Recommendations}

- Vaccinate patients early in kidney disease or prior to transplantation when possible

- Programs should implement vaccination protocols

- Further studies are necessary to determine the optimal vaccination schedules in CKD and KT patients

- The ACIP provides current vaccine recommendations in the USA

\section{Conclusions}

Vaccination remains an important tool for a vaccine-preventable infection in patients with CKD and KT recipients. Opportunity exists for improving vaccine uptake in this patient population. Further studies are warranted to evaluate the optimal vaccine regimen in the setting of immunosuppression.

\section{Compliance with Ethical Standards}

\section{Conflict of Interest}

T.B. has no conflict of interests to declare.

C.K. serves on a data safety monitoring board for Merck and is a member of the Advisory Board on Immunization Practice at the Centers for Disease Control and Prevention, Atlanta, Georgia.

\section{References and Recommended Reading}

1. Pereira MR, Mohan S, Cohen DJ, Husain SA, Dube GK, Ratner LE, Arcasoy S, Aversa MM, Benvenuto LJ, Dadhania DM, Kapur S, Dove LM, Brown RS Jr, Rosenblatt RE, Samstein B, Uriel N, Farr MA, Satlin M, Small CB, Walsh TJ, Kodiyanplakkal RP, Miko BA, Aaron JG, Tsapepas DS, Emond JC, Verna EC. COVID19 in solid organ transplant recipients: Initial report from the US epicenter. Am J Transplant. 2020 Jul;20(7):1800-1808. doi: 10.1111/ajt.15941. Epub 2020 May 10. PMID: 32330343; PMCID: PMC7264777.

2. Ranabothu S, Kanduri SR, Nalleballe $\mathrm{K}$, Cheungpasitporn W, Onteddu S, Kovvuru K. Outcomes of COVID-19 in Solid Organ Transplants. Cureus. 2020 Nov 5;12(11):e11344. doi: 10.7759/ cureus.11344. PMID: 33173653; PMCID: PMC7647837.

3. Ou MT, Boyarsky BJ, Motter JD, Greenberg RS, Teles AT, Ruddy JA, Krach MR, Jain VS, Werbel WA, Avery RK, Massie AB, Segev DL, Garonzik-Wang JM. Safety and Reactogenicity of 2 Doses of SARS-CoV-2 Vaccination in Solid Organ Transplant Recipients. Transplantation. 2021 Apr 9. doi: 10.1097/TP.0000000000003780. Epub ahead of print. PMID: 33859151.

4. Boyarsky BJ, Werbel WA, Avery RK, et al. Immunogenicity of a Single Dose of SARS-CoV-2 Messenger RNA Vaccine in Solid Organ Transplant Recipients. JAMA. Published online March 15, 2021. doi:10.1001/ jama.2021.4385

5. Dos Santos G, Haguinet F, Cohet C, Webb D, Logie J, Ferreira GL, et al. Risk of solid organ transplant 
rejection following vaccination with seasonal trivalent inactivated influenza vaccines in England: a selfcontrolled case-series. Vaccine. 2016;34(31):3598606. https://doi.org/10.1016/j.vaccine.2016.05.016.

6. Bosaeed M, Kumar D. Seasonal influenza vaccine in immunocompromised persons. Hum Vaccin Immunother. 2018;14(6):1311-22. https://doi.org/ $10.1080 / 21645515.2018 .1445446$.

7. Schillie S, Vellozzi C, Reingold A, Harris A, Haber P, Ward JW, et al. Prevention of hepatitis B virus infection in the United States: recommendations of the Advisory Committee on Immunization Practices. MMWR Recomm Rep. 2018b;67(1):1-31. https://doi.org/10. 15585/mmwr.rr6701a1.

8. Dooling KL, Guo A, Patel M, Lee GM, Moore K, Belongia EA, et al. Recommendations of the Advisory Committee on Immunization Practices for use of herpes zoster vaccines. MMWR Morb Mortal Wkly Rep. 2018;67(3):103-8. https://doi.org/10.15585/mmwr. mm6703a5.

9. Centers for Disease C, Prevention. Use of 13-valent pneumococcal conjugate vaccine and 23-valent pneumococcal polysaccharide vaccine for adults with immunocompromising conditions: recommendations of the Advisory Committee on Immunization Practices (ACIP). MMWR Morb Mortal Wkly Rep. 2012;61(40):816-9.

10. Petrosky E, Bocchini JA Jr, Hariri S, Chesson H, Curtis $\mathrm{CR}$, Saraiya M, et al. Use of 9-valent human papillomavirus (HPV) vaccine: updated HPV vaccination recommendations of the advisory committee on immunization practices. MMWR Morb Mortal Wkly Rep. 2015;64(11):300-4.

11. Wong KK, Burdette E, Mahon BE, Mintz ED, Ryan ET, Reingold AL. Recommendations of the Advisory Committee on Immunization Practices for use of cholera vaccine. MMWR Morb Mortal Wkly Rep. 2017;66(18):482-5. https://doi.org/10.15585/mmwr. mm6618a6.

12. Clemente WT, Pierrotti LC, Abdala E, Morris MI, Azevedo LS, Lopez-Velez R, et al. Recommendations for management of endemic diseases and travel medicine in solid-organ transplant recipients and donors: Latin America. Transplantation. 2018;102(2):193208. https://doi.org/10.1097/TP.0000000000002027.

13. Chong PP, Avery RK. A comprehensive review of immunization practices in solid organ transplant and hematopoietic stem cell transplant recipients. Clin Ther. 2017;39(8):1581-98. https://doi.org/10.1016/j. clinthera.2017.07.005.

14. Tseng HF, Luo Y, Shi J, Sy LS, Tartof SY, Sim JJ, et al. Effectiveness of herpes zoster vaccine in patients 60 years and older with end-stage renal disease. Clin Infect Dis. 2016;62(4):462-7. https://doi.org/10.1093/cid/ civ930.

15. Baluch A, Humar A, Eurich D, Egli A, Liacini A, Hoschler K, et al. Randomized controlled trial of highdose intradermal versus standard-dose intramuscular influenza vaccine in organ transplant recipients. Am J
Transplant Off J Am Soc Transplant Am Soc Transplant Surg. 2013;13(4):1026-33. https://doi.org/10.1111/ ajt.12149.

16. Kumar D, Blumberg EA, Danziger-Isakov L, Kotton CN, Halasa NB, Ison MG, et al. Influenza vaccination in the organ transplant recipient: review and summary recommendations. Am J Transplant Off J Am Soc Transplant Am Soc Transplant Surg. 2011;11(10):2020-30. https://doi.org/10.1111/j.1600-6143.2011.03753.x.

17. Siegrist CA, Ambrosioni J, Bel M, Combescure C, Hadaya K, Martin PY, et al. Responses of solid organ transplant recipients to the AS03-adjuvanted pandemic influenza vaccine. Antivir Ther. 2012;17(5):893-903. https://doi.org/10.3851/IMP2103.

18. Danziger-Isakov L, Cherkassky L, Siegel H, McManamon M, Kramer K, Budev M, et al. Effects of influenza immunization on humoral and cellular alloreactivity in humans. Transplantation. 2010;89(7):838-44. https://doi.org/10.1097/TP. ob013e3181ca56f8.

19. Chong PP, Handler L, Weber DJ. A systematic review of safety and immunogenicity of influenza vaccination strategies in solid organ transplant recipients. Clin Infect Dis. 2018;66(11):1802-11. https://doi.org/10. 1093/cid/cix1081.

20. Kumar D, Campbell P, Hoschler K, Hidalgo L, AlDabbagh M, Wilson L, et al. Randomized controlled trial of adjuvanted versus nonadjuvanted influenza vaccine in kidney transplant recipients. Transplantation. 2016;100(3):662-9. https://doi.org/10.1097/TP. 0000000000000861.

21. Fernandez-Ruiz M, Lumbreras C, Arrazola MP, LopezMedrano F, Andres A, Morales JM, et al. Impact of squalene-based adjuvanted influenza vaccination on graft outcome in kidney transplant recipients. Transpl Infect Dis. 2015;17(2):314-21. https://doi.org/10. 1111/tid.12355.

22. Kim DK, Riley LE, Hunter P. Advisory Committee on Immunization Practices recommended immunization schedule for adults aged 19 years or older-United States, 2018. MMWR Morb Mortal Wkly Rep. 2018;67(5):158-60. https://doi.org/10.15585/mmwr. mm6705e3.

23. Cavdar C, Sayan M, Sifil A, Artuk C, Yilmaz N, Bahar H, et al. The comparison of antibody response to influenza vaccination in continuous ambulatory peritoneal dialysis, hemodialysis and renal transplantation patients. Scand J Urol Nephrol. 2003;37(1):71-6.

24. Chang CC, Chang YS, Chen WS, Chen YH, Chen JH. Effects of annual influenza vaccination on morbidity and mortality in patients with systemic lupus erythematosus: a nationwide cohort study. Sci Rep. 2016;6:37817. https://doi.org/10.1038/srep37817.

25. Cohen-Hagai K, Kotliroff A, Rozenberg I, Korzets Z, Zitman-Gal T, Benchetrit S. Effectiveness of influenza vaccine in hemodialyzed patients: a retrospective study. Ther Apher Dial. 2018;23:38-43. https://doi. org/10.1111/1744-9987.12742. 
26. Noh JY, Song JY, Choi WS, Lee J, Seo YB, Kwon YJ, et al. Immunogenicity of trivalent influenza vaccines in patients with chronic kidney disease undergoing hemodialysis: MF59-adjuvanted versus non-adjuvanted vaccines. Hum Vaccin Immunother. 2016;12(11):2902-8. https://doi.org/10.1080/21645515.2016.1191717.

27. Chon WJ, Kadambi PV, Harland RC, Thistlethwaite JR, West BL, Udani S, et al. Changing attitudes toward influenza vaccination in U.S. kidney transplant programs over the past decade. Clin J Am Soc Nephrol. 2010;5(9):1637-41. CJN.00150110 [pii]. https://doi. org/10.2215/CJN.00150110.

28. Hurst FP, Lee JJ, Jindal RM, Agodoa LY, Abbott KC. Outcomes associated with influenza vaccination in the first year after kidney transplantation. Clin J Am Soc Nephrol. 2011;6(5):1192-7. https://doi.org/10.2215/ CJN.05430610.

29. Helantera I, Anttila VJ, Lappalainen M, Lempinen M, Isoniemi $\mathrm{H}$. Outbreak of influenza a(H1N1) in a kidney transplant unit-protective effect of vaccination. Am J Transplant Off J Am Soc Transplant Am Soc Transplant Surg. 2015;15(9):2470-4. https://doi.org/10. 1111/ajt.13285.

30. Natori Y, Shiotsuka M, Slomovic J, Hoschler K, Ferreira $\mathrm{V}$, Ashton $\mathrm{P}$, et al. A double-blind, randomized trial of high-dose vs standard-dose influenza vaccine in adult solid-organ transplant recipients. Clin Infect Dis. 2018;66(11):1698-704. https://doi.org/10.1093/cid/ cix1082.

31. Recommendations for preventing transmission of infections among chronic hemodialysis patients. MMWR Recomm Rep. 2001 Apr 27;50(RR-5):1-43. PMID: 11349873.

32. Stevens CE, Alter HJ, Taylor PE, Zang EA, Harley EJ, Szmuness W. Hepatitis B vaccine in patients receiving hemodialysis. Immunogenicity and efficacy. N Engl J Med. 1984;311(8):496-501. https://doi.org/10.1056/ NEJM198408233110803.

33. Schillie S, Harris A, Link-Gelles R, Romero J, Ward J, Nelson N. Recommendations of the Advisory Committee on Immunization Practices for use of a hepatitis $B$ vaccine with a novel adjuvant. MMWR Morb Mortal Wkly Rep. 2018a;67(15):455-8. https://doi.org/10. 15585/mmwr.mm6715a5.

34. Janssen RS, Mangoo-Karim R, Pergola PE, Girndt M, Namini H, Rahman S, et al. Immunogenicity and safety of an investigational hepatitis B vaccine with a toll-like receptor 9 agonist adjuvant (HBsAg-1018) compared with a licensed hepatitis $B$ vaccine in patients with chronic kidney disease. Vaccine. 2013;31(46):530613. https://doi.org/10.1016/j.vaccine.2013.05.067.

35. Friedrich P, Sattler A, Muller K, Nienen M, Reinke P, Babel N. Comparing humoral and cellular immune response against HBV vaccine in kidney transplant patients. Am J Transplant Off J Am Soc Transplant Am Soc Transplant Surg. 2015;15(12):3157-65. https://doi. org/10.1111/ajt.13380.

36. Lindemann $\mathrm{M}$, Zaslavskaya $\mathrm{M}$, Fiedler $\mathrm{M}$, Wilde $\mathrm{B}$, Heinemann FM, Heinold A, et al. Humoral and cellular responses to a single dose of Fendrix in renal transplant recipients with non-response to previous hepatitis B vaccination. Scand J Immunol. 2017;85(1):51-7. https://doi.org/10.1111/sji.12497.

37. Slinin Y, Foley RN, Collins AJ. Clinical epidemiology of pneumonia in hemodialysis patients: the USRDS waves 1, 3, and 4 study. Kidney Int. 2006;70(6):113541. https://doi.org/10.1038/sj.ki.5001714.

38. Vandecasteele SJ, Ombelet S, Blumental S, Peetermans $\mathrm{WE}$. The $\mathrm{ABC}$ of pneumococcal infections and vaccination in patients with chronic kidney disease. Clin Kidney J. 2015;8(3):318-24.

39. Vandecasteele SJ, De Bacquer D, Caluwe R, Ombelet S, Van Vlem B. Immunogenicity and safety of the 13valent pneumococcal conjugate vaccine in 23 -valent pneumococcal polysaccharide vaccine-naive and preimmunized patients under treatment with chronic haemodialysis: a longitudinal quasi-experimental phase IV study. Clin Microbiol Infect. 2017;24:65-71. https://doi.org/10.1016/j.cmi.2017.05.016.

40. Matanock A, Lee G, Gierke R, Kobayashi M, Leidner A, Pilishvili T. Use of 13-valent pneumococcal conjugate vaccine and 23-valent pneumococcal polysaccharide vaccine among adults aged $>/=65$ years: updated recommendations of the Advisory Committee on Immunization Practices. MMWR Morb Mortal Wkly Rep. 2019;68(46):1069-75. https://doi.org/10.15585/ mmwr.mm6846a5.

41. Kim DK, Hunter P. Recommended adult immunization schedule, United States, 2019. Ann Intern Med. 2019;170(3):182-92.

42. Mitra S, Stein GE, Bhupalam S, Havlichek DH. Immunogenicity of 13-valent conjugate pneumococcal vaccine in patients 50 years and older with end-stage renal disease and on dialysis. Clin Vaccine Immunol. 2016;23(11):884-7. https://doi.org/10.1128/CVI. 00153-16.

43. Fuchshuber A, Kuhnemund O, Keuth B, Lutticken R, Michalk D, Querfeld U. Pneumococcal vaccine in children and young adults with chronic renal disease. Nephrol Dial Transplant. 1996;11(3):468-73.

44. Dendle C, Stuart RL, Polkinghorne KR, Balloch A, Kanellis J, Ling J, et al. Seroresponses and safety of 13valent pneumococcal conjugate vaccination in kidney transplant recipients. Transpl Infect Dis. 2018;20(2):e12866. https://doi.org/10.1111/tid. 12866.

45. Kumar D, Welsh B, Siegal D, Chen MH, Humar A. Immunogenicity of pneumococcal vaccine in renal transplant recipients-three year follow-up of a randomized trial. Am J Transplant Off J Am Soc Transplant Am Soc Transplant Surg. 2007;7(3):633-8. https://doi. org/10.1111/j.1600-6143.2007.01668.x.

46. Lindemann M, Heinemann FM, Horn PA, Witzke O. Long-term response to vaccination against pneumococcal antigens in kidney transplant recipients. Transplantation. 2012;94(1):50-6. https://doi.org/10.1097/ TP.0b013e318250fc8c. 
47. Havers FP, Moro PL, Hunter P, Hariri S, Bernstein H. Use of tetanus toxoid, reduced diphtheria toxoid, and acellular pertussis vaccines: updated recommendations of the Advisory Committee on Immunization Practices-United States, 2019. MMWR Morb Mortal Wkly Rep. 2020;69(3):77-83. https://doi.org/10. 15585/mmwr.mm6903a5.

48. Girndt $\mathrm{M}$, Pietsch $\mathrm{M}$, Kohler H. Tetanus immunization and its association to hepatitis B vaccination in patients with chronic renal failure. Am J Kidney Dis. 1995;26(3):454-60. https://doi.org/10.1016/02726386(95)90491-3.

49. Kruger S, Seyfarth M, Sack K, Kreft B. Defective immune response to tetanus toxoid in hemodialysis patients and its association with diphtheria vaccination. Vaccine. 1999;17(9-10):1145-50. https://doi.org/10. 1016/s0264-410x(98)00334-x.

50. Huzly D, Neifer S, Reinke P, Schroder K, Schonfeld C, Hofmann $\mathrm{T}$, et al. Routine immunizations in adult renal transplant recipients. Transplantation. 1997;63(6):839-45. https://doi.org/10.1097/ 00007890-199703270-00008.

51. Danziger-Isakov L, Kumar D, Practice AICo. Vaccination of solid organ transplant candidates and recipients: guidelines from the American society of transplantation infectious diseases community of practice. Clin Transplant. 2019;33(9):e13563. https://doi.org/ $10.1111 /$ ctr.13563.

52. Schulman SL, Deforest A, Kaiser BA, Polinsky MS, Baluarte HJ. Response to measles-mumps-rubella vaccine in children on dialysis. Pediatr Nephrol. 1992;6(2):187-9. https://doi.org/10.1007/ bf00866312.

53. Kano H, Mizuta K, Sakakihara Y, Kato H, Miki Y, Shibuya N, et al. Efficacy and safety of immunization for pre- and post-liver transplant children. Transplantation. 2002;74(4):543-50. https://doi.org/10.1097/ 00007890-200208270-00020.

54. Shinjoh M, Miyairi I, Hoshino K, Takahashi T, Nakayama T. Effective and safe immunizations with live-attenuated vaccines for children after living donor liver transplantation. Vaccine. 2008;26(52):6859-63. https://doi.org/10.1016/j.vaccine.2008.09.076.

55. Marin M, Guris D, Chaves SS, Schmid S, Seward JF. Prevention of varicella: recommendations of the Advisory Committee on Immunization Practices (ACIP). MMWR Recomm Rep. 2007;56(RR-4):1-40.

56. Lin SY, Liu JH, Lin CL, Tsai IJ, Chen PC, Chung CJ, et al. A comparison of herpes zoster incidence across the spectrum of chronic kidney disease, dialysis and transplantation. Am J Nephrol. 2012;36(1):27-33. https:// doi.org/10.1159/000339004.

57. Vink P, Ramon Torrell JM, Sanchez Fructuoso A, Kim SJ, Kim SI, Zaltzman J, et al. Immunogenicity and safety of the adjuvanted recombinant zoster vaccine in chronically immunosuppressed adults following renal transplant: a phase 3, randomized clinical trial. Clin Infect Dis. 2020;70(2):181-90. https://doi.org/10. 1093/cid/ciz177.
58. Kates OS, Fisher CE, Stankiewicz-Karita HC, Shepherd AK, Church EC, Kapnadak SG, et al. Earliest cases of coronavirus disease 2019 (COVID-19) identified in solid organ transplant recipients in the United States. Am J Transplant Off J Am Soc Transplant Am Soc Transplant Surg. 2020a;20:1885-90. https://doi.org/ 10.1111/ajt.15944.

59. Zhu L, Xu X, Ma K, Yang J, Guan H, Chen S, et al. Successful recovery of COVID-19 pneumonia in a renal transplant recipient with long-term immunosuppression. Am J Transplant Off J Am Soc Transplant Am Soc Transplant Surg. 2020;20:1859-63. https://doi.org/10. 1111/ajt.15869.

60. Banerjee D, Popoola J, Shah S, Ster IC, Quan V, Phanish M. COVID-19 infection in kidney transplant recipients. Kidney Int. 2020;97(6):1076-82. https:// doi.org/10.1016/j.kint.2020.03.018.

61. Zhong Z, Zhang Q, Xia H, Wang A, Liang W, Zhou W, et al. Clinical characteristics and immunosuppressant management of coronavirus disease 2019 in solid organ transplant recipients. Am J Transplant Off J Am Soc Transplant Am Soc Transplant Surg. 2020;20:1916-21. https://doi.org/10.1111/ajt.15928.

62. Fernandez-Ruiz M, Andres A, Loinaz C, Delgado JF, Lopez-Medrano F, San Juan R, et al. COVID-19 in solid organ transplant recipients: a single-center case series from Spain. Am J Transplant Off J Am Soc Transplant Am Soc Transplant Surg. 2020;20:1849-58. https:// doi.org/10.1111/ajt.15929.

63. Kates OS, Haydel BM, Florman SS, Rana MM, Chaudhry ZS, Ramesh MS, et al. COVID-19 in solid organ transplant: a multi-center cohort study. Clin Infect Dis. 2020b. https://doi.org/10.1093/cid/ciaa1097.

64. Cheng Y, Luo R, Wang K, Zhang M, Wang Z, Dong L, et al. Kidney disease is associated with in-hospital death of patients with COVID-19. Kidney Int. 2020;97(5):829-38. https://doi.org/10.1016/j.kint. 2020.03.005.

65. Columbia University Kidney Transplant P. Early description of coronavirus 2019 disease in kidney transplant recipients in New York. J Am Soc Nephrol. 2020;31(6):1150-6. https://doi.org/10.1681/ASN. 2020030375.

66. Covid C, COVID C, COVID C, Chow N, Fleming-Dutra $\mathrm{K}$, Gierke R, et al. Preliminary estimates of the prevalence of selected underlying health conditions among patients with coronavirus disease 2019-United States, February 12-March 28, 2020. Morb Mortal Wkly Rep. 2020;69(13):382.

67. Thanh Le T, Andreadakis Z, Kumar A, Gomez Roman $\mathrm{R}$, Tollefsen S, Saville M, et al. The COVID-19 vaccine development landscape. Nat Rev Drug Discov. 2020;19(5):305-6. https://doi.org/10.1038/d41573020-00073-5.

68. Kim DK, Riley LE, Harriman KH, Hunter P, Bridges CB. Advisory Committee on Immunization Practices recommended immunization schedule for adults aged 19 years or older-United States, 2017. MMWR Morb 
Mortal Wkly Rep. 2017;66(5):136-8. https://doi.org/ 10.15585/mmwr.mm6605e2.

69. Patton ME, Stephens D, Moore K, MacNeil JR. Updated recommendations for use of MenB-FHbp serogroup B meningococcal vaccine-Advisory Committee on Immunization Practices, 2016. MMWR Morb Mortal Wkly Rep. 2017;66(19):509-13. https://doi.org/10. 15585/mmwr.mm6619a6.

70. Wyplosz B, Derradji O, Hong E, Francois H, Durrbach A, Duclos-Vallee JC, et al. Low immunogenicity of quadrivalent meningococcal vaccines in solid organ transplant recipients. Transpl Infect Dis.

2015;17(2):322-7. https://doi.org/10.1111/tid 12359.

71. Benamu E, Montoya JG. Infections associated with the use of eculizumab: recommendations for prevention and prophylaxis. Curr Opin Infect Dis.

2016;29(4):319-29. https://doi.org/10.1097/QCO. 0000000000000279 .

72. Kotton CN, Kroger AT, Freedman DO. Chapter 5: travelers with additional considerations: immunocompromised travelers. 2020 Health Information for International Travel (available at https://wwwnc.cdc. gov/travel/yellowbook/2020/travelers-withadditional-considerations/immunocompromisedtravelers). Atlanta: Centers for Disease Control and Prevention; 2020.

73. Jeon HJ, Ro H, Jeong JC, Koo TY, Han M, Min SI, et al. Efficacy and safety of hepatitis A vaccination in kidney transplant recipients. Transpl Infect Dis.

2014;16(3):511-5. https://doi.org/10.1111/tid. 12217.

74. CDC Yellow Book 2020: 2020 Health Information for International Travel (available at https://wwwnc.cdc. gov/travel/yellowbook/2020/travel-related-infectiousdiseases/yellow-fever). Atlanta: Centers for Disease Control and Prevention; 2020.

75. Azevedo LS, Lasmar EP, Contieri FL, Boin I, Percegona $\mathrm{L}$, Saber LT, et al. Yellow fever vaccination in organ transplanted patients: is it safe? A multicenter study. Transpl Infect Dis. 2012;14(3):237-41. https://doi. org/10.1111/j.1399-3062.2011.00686.x.
76. Wyplosz B, Burdet C, Francois H, Durrbach A, DuclosVallee JC, Mamzer-Bruneel MF, et al. Persistence of yellow fever vaccine-induced antibodies after solid organ transplantation. Am J Transplant Off J Am Soc Transplant Am Soc Transplant Surg. 2013;13(9):245861. https://doi.org/10.1111/ajt.12338.

77. Jonker EFF, Uijlings MAC, Visser LG, Soonawala D. Comparison of the immunogenicity of Dukoral(R) oral cholera vaccine between renal transplant recipients on either a calcineurin inhibitor or mycophenolate-a controlled trial. Vaccine. 2019;37(23):3133-9. https:// doi.org/10.1016/j.vaccine.2019.04.010.

78. Centers for Disease C, Prevention. Updated recommendations for use of VariZIG-United States, 2013. MMWR Morb Mortal Wkly Rep. 2013;62(28):574-6.

79. Croce E, Hatz C, Jonker EF, Visser LG, Jaeger VK, Buhler $\mathrm{S}$. Safety of live vaccinations on immunosuppressive therapy in patients with immune-mediated inflammatory diseases, solid organ transplantation or after bone-marrow transplantation-a systematic review of randomized trials, observational studies and case reports. Vaccine. 2017;35(9):1216-26. https://doi.org/ 10.1016/j.vaccine.2017.01.048.

80. Hocker B, Aguilar M, Schnitzler P, Pape L, Bald M, Konig J, et al. Vaccination titres pre- and posttransplant in paediatric renal transplant recipients and the impact of immunosuppressive therapy. Pediatr Nephrol. 2018;33(5):897-910. https://doi.org/10. 1007/s00467-017-3868-0.

81. Schulte K, Schierke H, Tamayo M, Hager L, Engehausen $\mathrm{R}$, Raspe $\mathrm{M}$, et al. Strategies for improving influenza vaccination rates in patients with chronic renal disease. Dtsch Arztebl Int. 2019;116(23-24):413-9. https:// doi.org/10.3238/arztebl.2019.0413.

\section{Publisher's Note}

Springer Nature remains neutral with regard to jurisdictional claims in published maps and institutional affiliations. 